\title{
ALTERNATIVE PHOSPHATIC FERTILISERS. NORTHLAND FARMERS, WEIGH THE EVIDENCE
}

\author{
C. DURING and G.E. MALDEN
}

Farmers Fertiliser Limited, Auckland.

\section{Abstract}

Fertilisers based on or enriched by reactive phosphate rock (RPR) compare favourably in price with superphosphate under certain conditions. The ultimate choice of fertiliser depends on three factors:- the agronomic effectiveness of phosphorus in RPR in different soils; the sulphur requirements of pasture and the effect of this on price; and the effect of high proportions of potassium chloride on the physical properties of fertilisers.

The rate of dissolution of RPR is reduced by high $\mathrm{pH}$ and high $\mathrm{P}$ and $\mathrm{Ca}$ concentrations in the ambient solution. The so-called gumland soils, recognisable by their bleached subsoils have higher $\mathrm{P}$ and $\mathrm{Ca}$ concentrations in the soils solution than other soils in Northland, $\mathrm{pH}$ and $\mathrm{P}$ status being equal. They also tend to lose more sulphate by leaching than other soils, so maintenance of requirements of their pastures for sulphur are very high. In addition many of the gumland soils need low rates of phosphorus but relatively high rates of potash. Pending further field evidence, therefore, RPR based or reinforced fertilisers at present are recommended for hill country and for soils derived from basic or semi-basic volcanic materials, provided the latter soils do not require a very high proportion of potassium chloride for pasture maintenance.

Keywords: Soil pH, calcium, phosphorus, pasture, organic matter, sulphur, potassium, superphosphate, phosphate rocks.

\section{INTRODUCTION}

The reserves of high analysis rock from which our superphosphate is made are gradually dwindling. Other phosphate rocks are in good supply but would produce single superphosphate of unacceptably low $\mathrm{P}$ content. Because of transport and spreading costs the ideal replacement fertiliser should contain more $\mathrm{P}$ than super phosphate. It should be an effective source of $\mathrm{P}$ on pasture and crop in all parts of this country and it should be, of course, inexpensive. Price alone eliminates several products, made overseas, that otherwise satisfy all our requirements. Because of this, the alternatives to superphosphate that at the present time appear worthy of consideration represent a compromise between quality and cost and use the so-called reactive phosphate rocks (RPR). These are naturally soft, porous, often sandy and dusty materials. They are not water soluble, but, provided they are ground to the minimum standard laid down by the 1984 Fertiliser Regulations they dissolve rapidly enough to maintain reasonably high phosphate fertility of permanent pasture on many of our soils. Northland, however, has a disproportionally large share of soils on which further experimental work is required before RPR based fertilisers can be whole-heartedly recommended. The risk involved in experimenting should not lie with the farmer. In this paper therefore, we shall discuss two aspects of RPR based fertilisers, their likely suitability on different types of Northland soils, and their cost.

\section{DESCRIPTION OF REACTIVE PHOSPHATE ROCK BASED FERTILISERS}

\section{Untreated, or ground and pelleted RPR}

Reactive phosphate rocks that are imported contain $12-15 \%$ P. Only good batches of Sechura rock, from Peru, can be used directly as fertilisers without prior treatment. Supplies of this material however, are erratic, the exploitation of natural deposits still awaits commercial development and physical properties of the rock may vary from shipment to shipment.

At present North Carolina and perhaps Jordanian RPR's are our best options, but they need grinding to qualify legally as fertilisers. 


\section{Partially Acidified RPR}

Grinding of RPR creates dust problems and pelletting is expensive. Partial acidu lation has great advantages; it makes a part of RPR water-soluble and thereby increases its speed of action. Furthermore, partially acidified materials can be granulated, avoiding the high cost of pelletting. Two types of partially acidified RPR's are being made commercially.

(a) PARR - Reactive Phosphate Rock Partially Acidified With Phosphoric Acid

This material has been used overseas for quite some time. For pasture maintenance in New Zealand 30\% acidification is considered to be adequate (Rajan and O'Connor 1985). The resulting fertiliser contains about $17 \% \mathrm{P}$ of which $60 \%$ is still in the form of RPR and the remainder is a triple superphosphate, but contains practically no sulphur. Also, without further investment in new equipment it is difficult to granulate to a dust-free state. Some is being imported in a granulated form from overseas.

\section{(b) Longlife Super}

This is the name given by Farmers Fertiliser Company to a product made by adding approximately three parts of reactive phosphate rock to seven parts of freshly made, hot, moist superphosphate that has been over-acidulated. The result is a mixture of superphosphate and partially acidulated RPR containing $11 \%$ total $\mathrm{P}$ and $8 \%$ sulphur. It is easier to granulate than PARR, and is slower acting than superphosphate but of a greater residual value.

\section{(c) Fortified}

This consists of $70 \%$ 'Longlife' and 30\% PARR, and contains nearly $12 \%$ effective P, $6 \%$ sulphur and mixes well with muriate of potash.

\section{REACTIVE PHOSPHATE ROCK AND SOIL TYPE}

The three soil characteristics that affect the rate of dissolution of phosphate rock are soil $\mathrm{pH}$, the level of $\mathrm{P}$ in the soil solution and the level of calcium in the soil solution. Most Northland soils are initially fairly acid, i.e. they have low pH (Soil Bureau 1954). To maintain high pasture production lime is added to reduce acidity, $\mathrm{pH} 5.5$ to $\mathrm{pH} 5.7$ being considered an adequate level. This range of $\mathrm{pH}$ values is not high enough to render RPRs ineffective, and farmers have the ability to see that it is not greatly exceeded. On the other hand the levels of $\mathrm{P}$ and $\mathrm{Ca}$ in the soil solution are not under the control of farmers, but may be just as important in determining the rate of dissolution of RPRs as $\mathrm{pH}$ (Khasawneh and Doll 1978).

At equal P fertility soil may have a very wide range of soil solution P levels, and at equal $\mathrm{pH}$ they may have a range of solution calcium levels. For instance in Northland sites judged to be of similar $\mathrm{P}$ fertility, about a hundredfold difference in $\mathrm{P}$ solution levels was found (During 1968). In terms of acidity this is equivalent to a range of two $\mathrm{pH}$ units. Solution calcium was measured on fewer sites and showed a much smaller range. In general highly $\mathrm{P}$ retentive soils have lower $\mathrm{P}$ and $\mathrm{Ca}$ concentrations in solution than soils of low P retention. Consequently it is assumed, that RPR based fertilisers dissolve more rapidly in soils with high, than with low $\mathrm{P}$ retention. In practice there could be several modifying factors. For instance at Whatawhata Hill Research Station, on a paddock containing soils of a wide range of $\mathrm{P}$ retention properties, solution calcium in the top $2.5 \mathrm{~cm}$ of soil was extremely low (During et al. 1984), with only a moderate range of $\mathrm{P}$ concentrations in solution, and no exceptionally high values. Solution calcium remained very low even after liming. This result was attributed to the masking effect of the very high organic matter content of the top $2.5 \mathrm{~cm}$ in that somewhat rootbound pasture. In Northland, on the other hand, the sites sampled had been recently cultivated. The above results suggest that on the old hill country swards of 
northern North Island, if not limed to excess, reactive phosphate rock based fertilisers may be effective over a wide range of soil types. On the other hand on intensively farmed land on easy contour on soils of very low $P$ retention, the use of these fertilisers may involve an unacceptable risk, unless long term field experiments prove otherwise. In Northland the most widely distributed soils with zero to low P retention are the Wharekohe, Te Kopuru, Hukerenui, Kara, Waikare and Pokapu soils. These so-called gumland soils are recognised by their pale colour in the top $10-20 \mathrm{~cm}$. They not only occupy a fair proportion of Northland farmland but also are frequently and intimately associated with other soils in the same paddock. They are very much more common on flat to undulating than on hilly and steep land.

\section{SULPHUR AND SOIL TYPE}

Reactive rock phosphates and the P enriched PARR's contain virtually no sulphur, but pastures in New Zealand, with very few exceptions need sulphur for maintenance. The MAF bulletin 'Fertiliser Recommendations for Pasture and Crops in New Zealand' (Sinclair and Saunders 1984), assesses sulphur requirements by estimating the likely rate of leaching but considers also closeness to the sea. Dealing with the latter point first, good but irregularly occurring pasture yield responses to sulphur close to the East Coast of Northland, and excellent yield responses close to the windy West Coast of the Buller District, have been observed (McNaught and During 1970). Very few pastures of New Zealand are entirely immune to sulphur deficiency irrespective of location. The rate at which sulphate leaches out of the effective reach of pasture roots depends on sulphate retention, drainage properties of soil and rainfall. Balance studies with sulphate and chemical analyses (During 1972) indicate that perhaps $90 \%$ of Northland soils have low sulphate retention properties in the top $8 \mathrm{~cm}$. The soils with high $\mathrm{S}$ retention are the friable volcanic clays, such as Kiripaka clay loam, but excluding the ironstone soils.

Highly retentive soils can store enough sulphur to supply pasture for several years, but in the long run, of course, sulphur physically lost in animal products, by transfer in excreta and by slowly proceeding leaching will need to be replaced. The remaining soils can be put into two groups:-

\section{Gumland Soils}

In relatively freely draining soils such as some Waikare clay loams and silt loams, applied sulphate, as in superphosphate, may be washed out of the range of pasture roots by as little as $250 \mathrm{~mm}$ rain. On less well drained sites sulphate may move sideways off the paddock, or if conditions are right, may diffuse into the topsoil and be protected against leaching by its very imperviousness (During 1972). Generally speaking, gumland soils should not be expected to retain applied sulphate for more than one year. Most at risk are the Wharekohe sandy loams and the freely draining Waikare silt loams. Therefore sulphate or sulphur should be applied on an annual basis, at a rate of not less than $1.2 \mathrm{~kg} / \mathrm{SU}$ (Sinclair and Saunders 1984).

\section{Soils Other Than The Gumlands}

They are not likely to require annual applications of sulphur for pasture maintenance. This statement rests on field trial results, mostly unpublished, although balance studies (During 1972) showed that sulphate not taken up by soil micro-organisms or herbage is completely washed out by a winter's normal rainfall. This group includes most hill soils and the so-called semi-volcanic soils (Brown granular clays). Provided they have been well topdressed with superphosphate in the past they may provide enough residual sulphur for pasture maintenance for a period of two years. It would be unduly risky to expect more than that. 
TABLE 1: Comparison of Cost of P Fertilisers.

\begin{tabular}{|c|c|c|c|c|c|}
\hline & $\begin{array}{c}\text { Super } \\
0-9-0-111\end{array}$ & $\begin{array}{c}\text { Longlife } \\
0-1 \text { 1-0-E }\end{array}$ & $\begin{array}{c}\text { Fortified } \\
0-13-0-6\end{array}$ & $\begin{array}{c}\text { PARR } \\
0-17-0-1\end{array}$ & $\begin{array}{r}\text { PARR + S } \\
\text { O-15-0-13 }\end{array}$ \\
\hline Price/tonne $(\$)$ & 167.44 & 176.80 & 243.25 & 370.90 & 413.20 \\
\hline Plant avail. P (\%) & 8 & 9.5 & 11.7 & 17 & 15 \\
\hline $\begin{array}{l}\text { Sowing rate } \\
(20 \mathrm{~kg} / \mathrm{ha}\end{array}$ & & & & & \\
\hline avail. P) & $250 \mathrm{~kg}$ & $210 \mathrm{~kg}$ & $170 \mathrm{~kg}$ & $120 \mathrm{~kg}$ & $134 \mathrm{~kg}$ \\
\hline Cost/ha & & & & & \\
\hline fertiliser only $(\$)$ & 41.86 & 37.14 & 41.36 & 44.52 & 55.38 \\
\hline Transport/ha & 7.00 & 5.88 & 4.76 & 3.36 & 3.75 \\
\hline Spreading/ha (\$) & 8.00 & 6.72 & 6.80 & 5.76 & 6.43 \\
\hline Total cost/ha (\$) & 56.86 & 49.74 & 52.92 & 53.64 & 65.56 \\
\hline Sulphur $\mathrm{kg} / \mathrm{ha}$ & 27.5 & 17.0 & 10.2 & 1.1 & 17.4 \\
\hline
\end{tabular}

1 N-P-K-S \%

\section{PRICE COMPARISONS}

Table 1 gives the cost of topdressing one hectare with $20 \mathrm{~kg}$ effective phosphorus. Spreading is by air, and assumed to cost $\$ 32.00 /$ tonne for application rates greater than $200 \mathrm{~kg} / \mathrm{ha}$, and to cost $\$ 48.00 /$ tonne for rates of $150 \mathrm{~kg}$ or less per hectare. Transport costs from works to airstrip at $\$ 28.00$ /tonne are based on $50 t$ fertiliser to be carried a distance of $100 \mathrm{~km}$.

Cost comparisons of materials of somewhat uncertain nutrient value are difficult to make. It has been assumed that the available $\mathrm{P}$ content of superphosphate is its citric acid rating (i.e. $8 \%$ ) and that of Longlife is $9.5 \%$. The latter estimate might be generous because it is likely that partly acidified but unground materials will contain some coarse particles. On most soils of Northland it will be necessary to add screen sulphur to PARR. It is the cheapest form of sulphur but also contains coarse particles that are of little agronomic value. On the other hand ground pelletted sulphur is not likely to be a practical alternative unless the cost of production can be substantially reduced. It should be noted that the sulphur content of 'Longlife' is marginal for pasture maintenance on many Northland soils and that of 'Fortified' probably too low for that purpose.

\section{POTASH MIXTURES}

Potassium deficiency is widespread in Northland, mainly on flat or undulating land but not confined to it alone (During 1972). Some of the gumland soils with low P retention are being topdressed with $30 \%$ or even $50 \%$ potassic superphosphate, but only up to $30 \%$ (by weight) of muriate of potash is incorporated into the fertiliser granules.

In partly acidified reactive rock fertilisers very much less muriate of potash is part of the granule. For this reason discrete KCI crystals exist and have a tendency to separate out during handling and transport. As the alternative fertilisers have a higher effective $\mathrm{P}$ rating than superphosphate, the proportion of muriate of potash that is added must increase correspondingly. The equivalents of $30 \%$ potassic superphosphate are $34 \%$ potassic 'Longlife Super', 50\% potassic sulphurised PARR, and 57\% potassic PARR. The use of 'chipped' muriate of potash reduces separation of the two types of fertilisers, but at an extra cost. This gives superphosphate an advantage in both handling and price on pasture that requires high rates of potash for maintenance. 


\section{CONCLUSIONS}

Northland encompasses soils with a wide range of $\mathrm{P}$ retentions, sulphate retentions and $\mathrm{P}$ and $\mathrm{Ca}$ concentration in their soil solutions. Field evaluation of RPR based fertilisers, with or without sulphur, have not yet covered this full range of soils, so that judgement of choice of fertiliser relies to a large extent on first principles and the known requirements for sulphur including its effect on cost. Relevant evidence suggests that the use of RPR containing fertilisers carries a low risk on hill country soils, and on some volcanic soils. On the other hand on gumland soils or on farms of easy contour consisting of a mixture of gumland and other soils the risk of getting unsatisfactory results from these fertilisers is high.

A mixture of overacidulated superphosphate and RPR, with a high superphosphate/RPR ratio is likely to be cheaper per unit of effective $P$ than superphosphate, provided it is used on the soils indicated above. The use, of RPR based fertilisers on gumland soils, or on farms having mixture of gumland and other soils should wait further research.

\section{References}

During, C. 1968. 9th ht. Cong. Soil Sci. Trans, Vol. 2: 281-292.

During, C. 1972. NZ Dept. of Agriculture Bull. 409, pp312

During, C.; Jackson, B.L.J.; Dyson, C.B. 1984. N.Z. J.agric. Res. 27: 383 387.

Khasawneh, R.D.; Doll, E.C. 1978. Aduances in Agronomy p. 159-206

McNaught, K.J.; During, C 1970 N.Z. J. agric. Res. 13: 567-590

Rajan, S.S.S.; O'Connor, M.B., 1985. N.Z. Fertilisers: 11-13.

Saunders, W.M.H.; Hogg, D.E., 1971. Internal MAF Report, 44pp.

Sinclair, A.G.; Saunders, W.M.H. 1984. 'Fertiliser and Lime Recommendations for Pasture and Crops in New Zealand', second rev. ed., MAF: 15-16.

Soil Bureau Bull. (n.s.5) 1954. General Survey of the Soils of North Island, New Zealand. pp286. 